\title{
Simple Mail Box Design of Dual Band Microstrip Patch Antenna for Wireless LAN Communications
}

\author{
K. Thana Pakkiam1, K. Baskaran², J. S. Mandeep ${ }^{3}$ \\ ${ }^{1,2}$ Faculty of Engineering Technology Infrastructure, Department of Electrical Electronic Engineering, Infrastructure \\ University Kuala Lumpur. 43000 Kajang, Selangor, Malaysia \\ ${ }^{3}$ Faculty of Engineering and Built Environment, Department of Electrical Electronic \& System Engineering, National \\ University of Malaysia. 43600 UKM Bangi, Selangor, Malaysia
}

\begin{tabular}{l}
\hline \hline Article Info \\
\hline Article history: \\
Received Aug 15, 2018 \\
Revised Oct 26, 2018 \\
Accepted Nov 06, 2018 \\
\hline
\end{tabular}

Keywords:

Dual band design

Mail box antenna

Mail box patch antenna

WLAN patch antenna

\begin{abstract}
In this paper, a simple mail box design of a dual band microstrip patch antenna, is proposed, designed, fabricated and measured for wireless LAN communications. The proposed antenna is designed using the TLC 30 (TACONIC) substrate, with a relative permittivity of 4.3 and substrate height of $1.6 \mathrm{~mm}$. It is designed to operate at $2.44 \mathrm{GHz}$ and $5.30 \mathrm{GHz}$ respectively. The proposed antenna is the size of $31 \mathrm{~mm} \times 34 \mathrm{~mm} \times 1.6 \mathrm{~mm}$ and is incited by a $50 \Omega$ micro strip feed line. The characteristics of the antenna are designed and the performance of the modelled antenna is evaluated using CST Microwave Studio. The return loss, radiation patterns and peak antenna gain of $6.5 \mathrm{dBi}$ for frequency $2.44 \mathrm{GHz}$ and $6.2 \mathrm{dBi}$ for $5.30 \mathrm{GHz}$ is separately and successfully plotted. The fabricated prototype exhibits an agreement between the measured and simulated return loss.
\end{abstract}

Copyright $(2018$ Institute of Advanced Engineering and Science. All rights reserved.

\section{Corresponding Author:}

K. Thana Pakkiam,

Faculty of Engineering Technology Infrastructure,

Department of Electrical Electronic Engineering,

Infrastructure University Kuala Lumpur. 43000 Kajang, Selangor, Malaysia.

Email: thanapakkiam@iukl.edu.my

\section{INTRODUCTION}

Current mobile users require portable, attractive, and lightweight multi technology electronics devices due to the remarkable advancement of wireless communication applications. A significant effort has been made over the years in the development of low profile multiband compact antenna designs along with new technologies and effective approaches. Scientists and engineers have developed patches, monopoles, and planar inverted-F antennas (FIFAs) to meet the growing demands for portable radios [1]. A microstrip antenna is an inexpensive antenna that has a number of advantages over other conventional antennas. These antennas are low in profile, lightweight and easily integrated with other electronic devices [2].

A number of antennas with dual-band operations such as circle slot antennas [3], stacked patches [4], metamaterial branch lines coupled [5], dual band dipoles [6] and slotted patches on ceramic materials [7] have been reported in the prior literature. However, most of these have complex structures and the useable bandwidths are reduced to a large percentage. A novel dual band dual-linearly-polarized proximity-coupled patch antenna is presented in [9]. A $10 \times 16 \mathrm{~mm}^{2}$ dual band-notched square monopole antenna was also proposed for ultra-wideband (UWB) applications [10]. And another approach to realizing a dual band antenna using a diamond shaped radiator for RFID application is also reported in [11]. But due to its large sizes, these antennas are not deemed suitable for the mobile devices as there is a space limitation within the chassis. Hence, as a result, further research is required to create a compatible structure that has a low profile, stable radiation pattern, and gain. 
In this particular study, a $31 \times 34 \mathrm{~mm}^{2}$ microstrip patch antenna was designed on a $1.6 \mathrm{~mm}$ thick FR4 substrate for WLAN applications. The antenna structure consists of a microstrip feed line, which is connected to a mail box shaped radiator. The presented antenna resonates at $2.4 \mathrm{GHz}$ and $5.2 \mathrm{GHz}$ for WLAN applications. The proposed prototype antenna performance further discussed in terms of the comparisons of the measured and simulated results.

\section{DESCRIPTION OF ANTENNA STRUCTURE}

The proposed dual band mail box patch antenna's geometry and dimensions for the Wireless LAN applications and reflections coefficients below $-10 \mathrm{~dB}$ as shown in Figure 1(a) and (b). The proposed dual band mail box patch antenna is contrived on a TLC 30 (TACONIC) substrate with the size of a $34 \times 31 \mathrm{~mm}^{2}$ and $1.5 \mathrm{~mm}$ thickness and a dielectric of 3.0. The relevant correlating dimensions of the designed parameter is shown in Table 1. The fractional ground plane is printed on the bottom of the substrate, and both the radiating element and the feeding line is printed on the top side of the substrate.

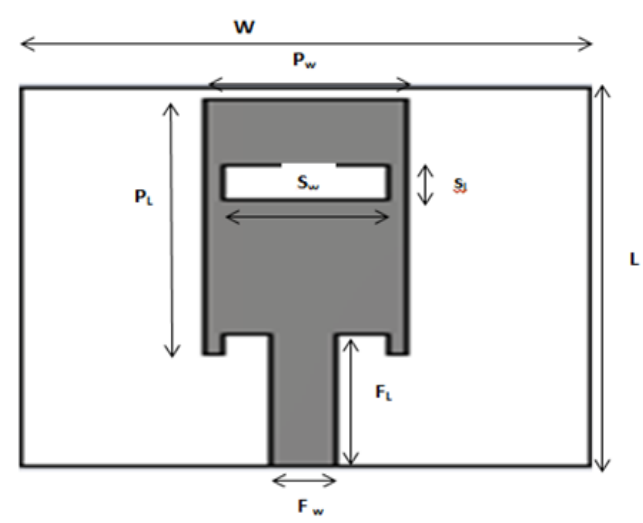

(a)

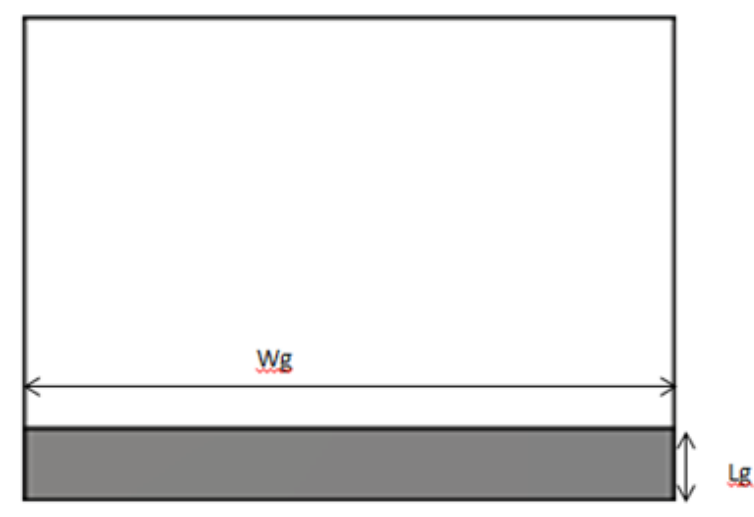

(b)

Figure 1. Proposed antenna structure view (a)front, (b)back

Table 1. The Complete Optimized Dimensions

\begin{tabular}{ccc}
\hline Parameter & Label & Dimension $(\mathrm{mm})$ \\
Substrate (Width and Lenth) & $\mathrm{WxL}$ & $31 \times 34$ \\
\hline \multirow{2}{*}{ Slot } & $\mathrm{S}_{\mathrm{l}}$ & 5 \\
& $\mathrm{~S}_{\mathrm{w}}$ & 9 \\
\multirow{2}{*}{ Patch } & $\mathrm{P}_{\mathrm{L}}$ & 23 \\
& $\mathrm{P}_{\mathrm{w}}$ & 12 \\
\multirow{2}{*}{ Feedline } & $\mathrm{F}_{\mathrm{L}}$ & 12 \\
& $\mathrm{~F}_{\mathrm{w}}$ & 3.6 \\
\multirow{2}{*}{ Ground } & $\mathrm{Wg}$ & 31 \\
& $\mathrm{Lg}$ & 5 \\
\hline
\end{tabular}

The fabricated antenna consists of a radiating element of a simple rectangle (PL), with another small rectangle slot (SL) scrapped off at size $9 \times 5 \mathrm{~mm}^{2}$, which is fed with a microstrip feed line to realize the $50 \Omega$ impedance. The microstrip feed line with the size of $3.6 \times 12 \mathrm{~mm}^{2}$ is connected to SMA to the port.

The CST microwave Studio [12] was utilized to search for the antenna's shape and dimensions. It is a commercially available software. Then, experimental adjustments were used to determine the optimal dimensions. Figure 2 (a) and (b) illustrates the print of the proposed fabricated antenna from both the front and back views. Substrate properties such as surface finishing and the fabrication processes like metallization and definition determines the accuracy of the line width and circuit performance. 


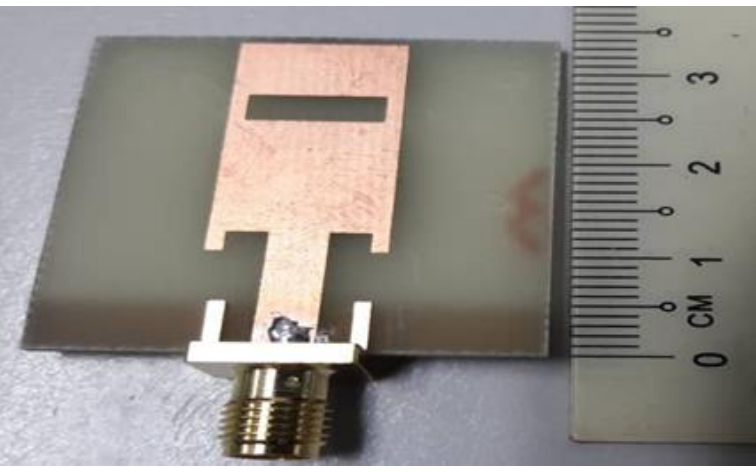

(a)

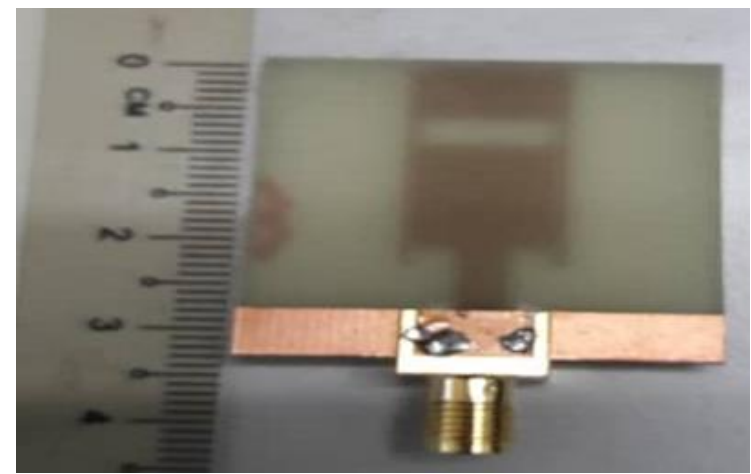

(b)

Figure 2. Front view (a)and back view (b)of the fabricated antenna photo

\section{THE SIMULATION AND MEASUREMENT OUTCOMES}

In this design, the progress of the proposed antenna is described in three stages. In order to obtain the resonant frequency and desired return loss, the proposed antenna is modified at each stage. As can be noticed in Figure 3(a) and Figure 3(b) respectively, that the feed line FL with $20 \mathrm{~mm}$ x $9 \mathrm{~mm}$ with scrapped rectangle slot generates a single resonant frequency of $2.16 \mathrm{GHz}$ and the return loss of $13.09 \mathrm{Db}$.

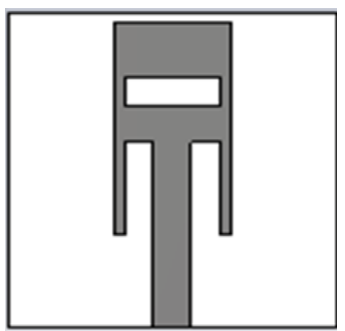

(a)

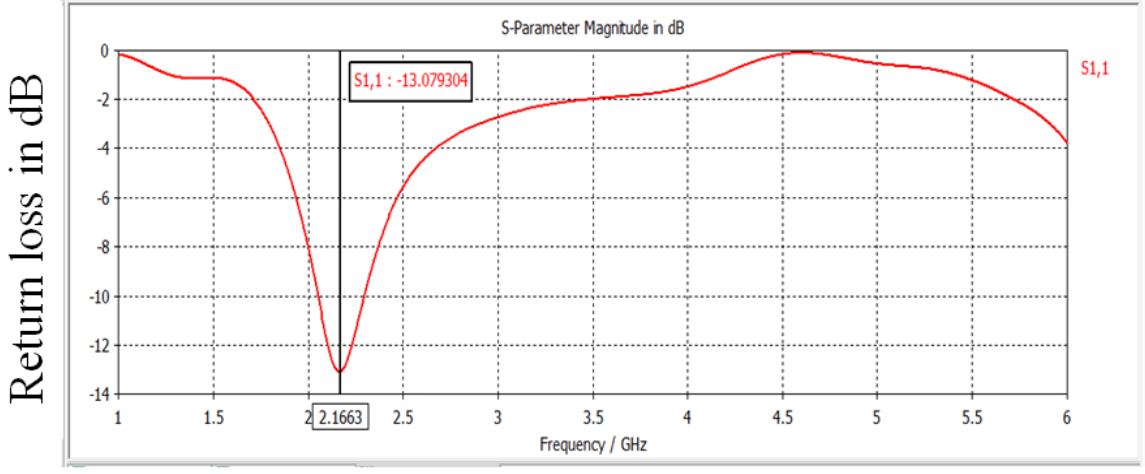

(b)

Figure 3. (a)Geometry of the proposed antenna FL=20 mm, (b)Return loss

When the feed line's height FL, is increased to $18 \mathrm{~mm}$, the second resonant frequency is generated; as seen in Figure 4(a), with a return loss at $11.406 \mathrm{~dB}$ and a resonant frequency of $4.98 \mathrm{GHz}$, as shown in Figure 4(b). However, this frequency still need to be improved in order to achieve the mandatory and required resonant frequency.

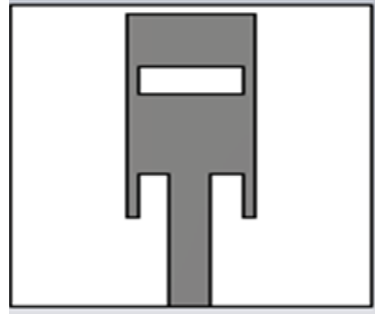

(a)

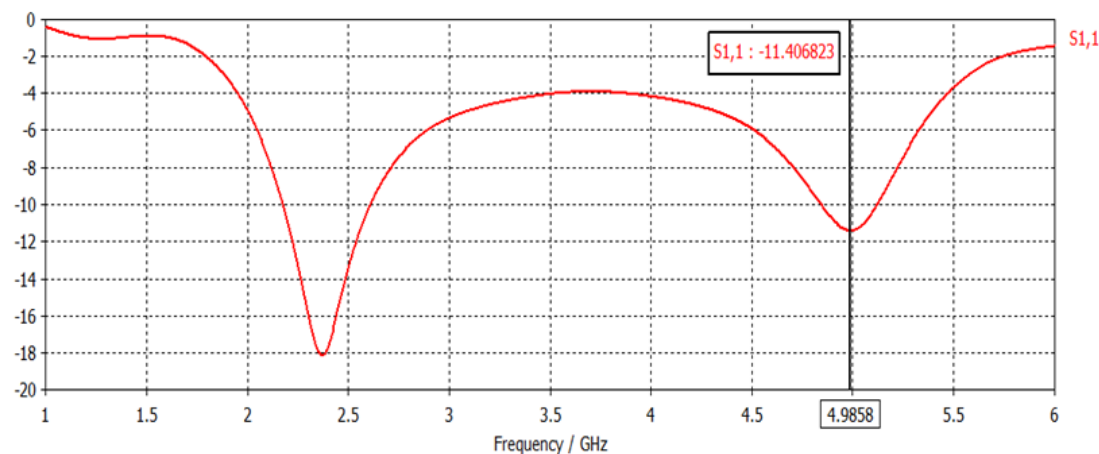

(b)

Figure 4. (a) Geometry of the proposed antenna $\mathrm{fl}=18 \mathrm{~mm}$, (b) return loss 
To generate the required resonant frequency at $2.4 \sim 2.484 \mathrm{GHz}$ and $5.15 \sim 5.35 \mathrm{GHz}$, the feed line radiator patch's height FL, has been reduced to $12 \mathrm{~mm}$ as shown in Figure 5 (a). The return loss for the considered patch is seen in Figure 5 (b). However, for all the three stages, the partial ground size remains the same at $31 \times 5 \mathrm{~mm}^{2}$. The proposed dual band mail box patch antenna by and large aims to attain a good performance for the Wireless LAN applications with a return loss below $-10 \mathrm{~dB}$.

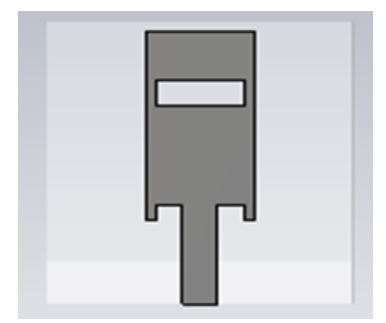

(a)

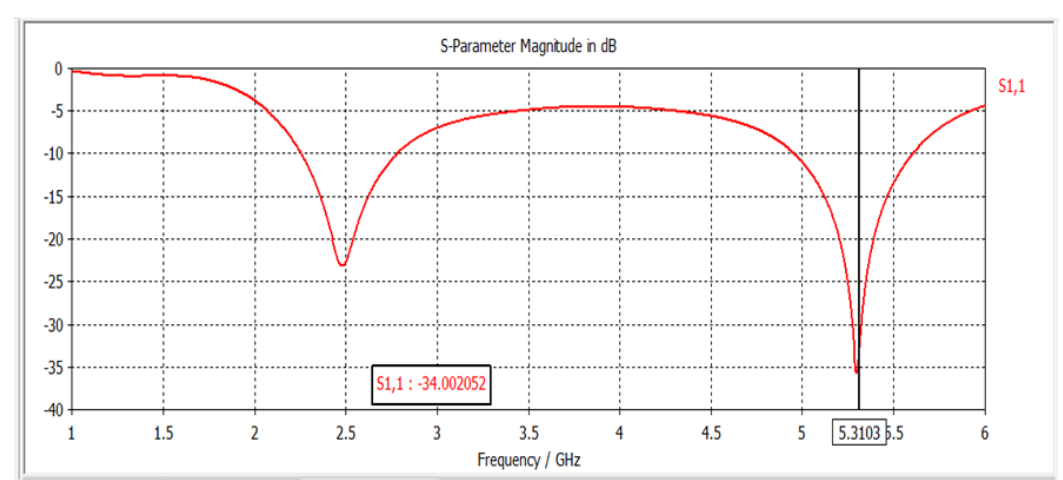

(b)

Figure 5. (a) Geometry of the proposed antenna with FL=12 $\mathrm{mm}$, (b) return loss

A prototype of the proposed antenna is manufactured as portrayed in Figure 2, and its characteristics are accordingly measured. The result of the return loss is measured using a Rhode and Schwarz Vector Network Analyzer (Model ZVL 30) that was readily available at the IUKL University Laboratory.

The measured and simulated return loss for the proposed antenna against the resonant frequency are plotted in Figure 6. From the results, it can be established that both resonant modes is to achieve a $-10 \mathrm{~dB}$ for simulations at $2.44 \mathrm{GHz}$ and $5.23 \mathrm{GHz}$. Likewise, the measurements of the resonant modes of $2.43 \mathrm{GHz}$ and $5.22 \mathrm{GHz}$ are also successfully reported. The return loss for both the simulation and measurements are 23.17 $\mathrm{dB}, 35.74 \mathrm{~dB}$ for the first and second mode, respectively and $27.31 \mathrm{~dB}$ and $21.54 \mathrm{~dB}$ for the first and second mode, respectively. These meets the specifications of the Wireless LAN applications.

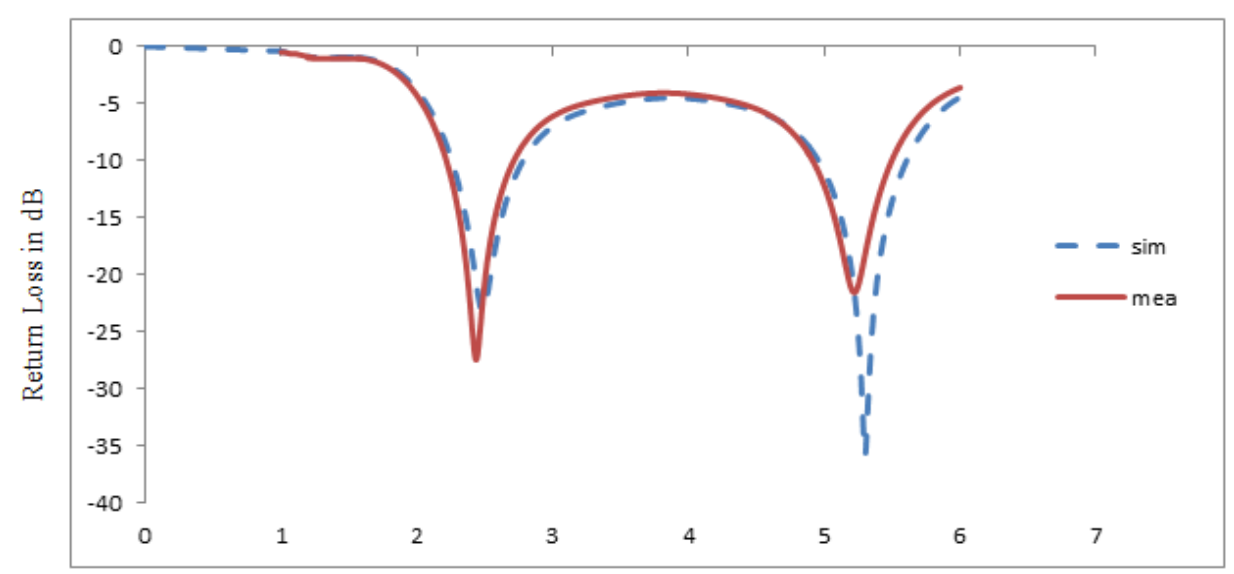

Frequency in $\mathrm{GHz}$

Figure 6. Simulated (dashed) and measured (solid) return loss of the proposed antenna

Figure 7 shows the normalized but simulated and the measured far field radiation patterns on the Eplane and $\mathrm{H}$-planes for its resonant frequencies at $\mathrm{f}=2.44 \mathrm{GHz}$ and $5.30 \mathrm{GHz}$. It is seen that the course of radiation is evenly dispersed. The resonant frequencies, both appears to have a figure eight bidirectional patterns in E-plane and omnidirectional patterns in H-planes. These plots imply that the radiation pattern of the design antenna are acceptable for the dual band operation. 


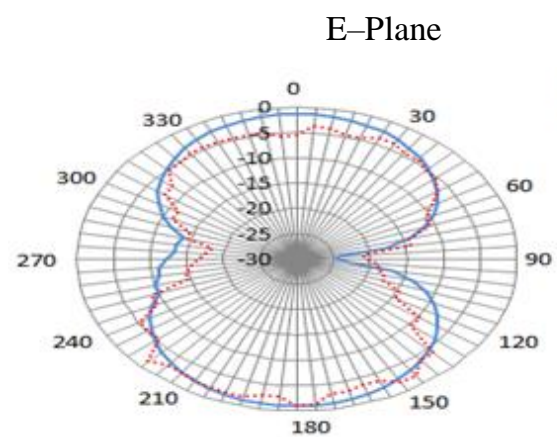

(a)
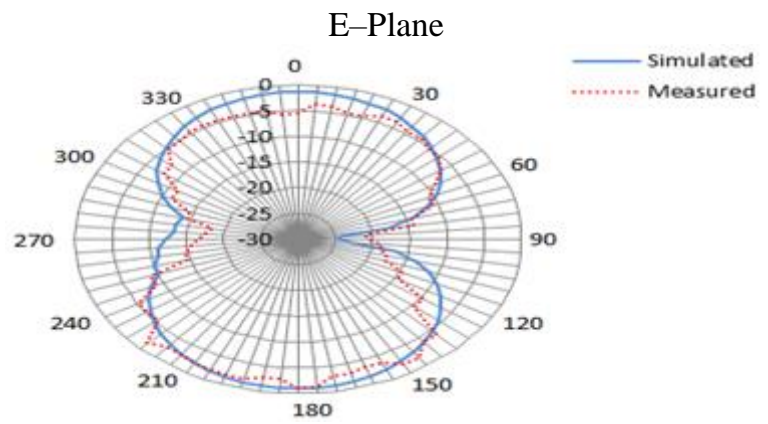
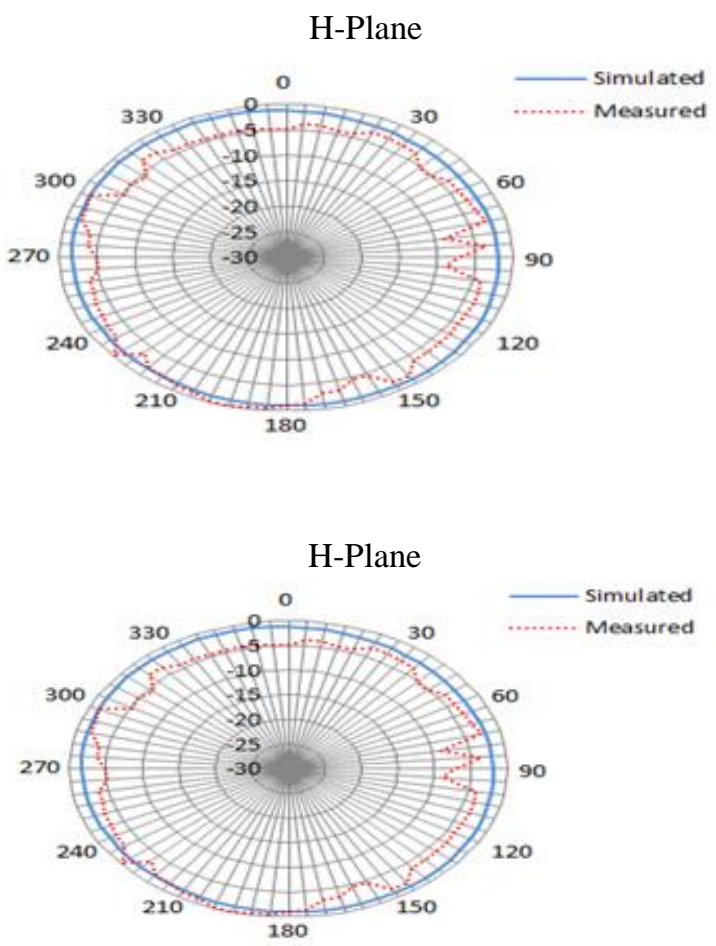

(b)

Figure 7. The radiation pattern of the design antenna (a) $2.44 \mathrm{GHz}$, (b) $5.30 \mathrm{GHz}$

Figure 8 shows that simulated and measured peak gain of the proposed antenna. The peak of the antenna gain observed at $2.44 \mathrm{GHz}$, and it shows a $6.5 \mathrm{dBi}$ and $6.2 \mathrm{dBi}$ respectively. The gain variations are approximately $0.3 \mathrm{dBi}$. Similarly at $5.30 \mathrm{GHz}$, the maximum concentrated radiation gain is approximately around $8 \mathrm{dBi}$ and $7 \mathrm{dBi}$. The gain variation is $1 \mathrm{dBi}$. The performance of antenna is influenced by the scrapped slot and partial ground patches on the suggested antenna.

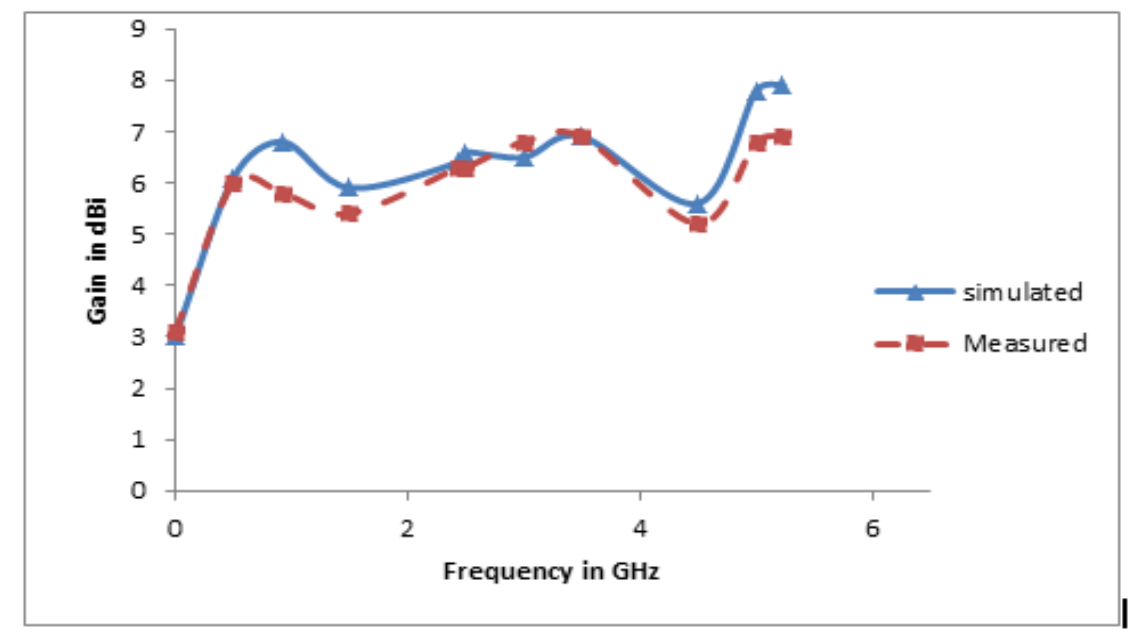

Figure 8. Simulated and measured gain in $\mathrm{dBi}$ of the antenna

\section{CONCLUSION}

The design of the simple mail box patch antenna for Wireless LAN applications is proposed, design, fabricated and measured successfully. The antenna resonates at $2.44 \mathrm{GHz}$ and $5.30 \mathrm{GHz}$ with good return loss of $23.05 \mathrm{~dB}$ and $35.564 \mathrm{~dB}$ respectively. The antenna attains an omnidirectional radiation pattern with a 
power gain of $6.5 \mathrm{dBi}$ for $2.44 \mathrm{GHz}$ and $8 \mathrm{dBi}$ for $5.30 \mathrm{GHz}$. The proposed antenna is extremely compact, and can easily be fabricated. It is also fed with a $50 \Omega$ microstrip line; which marks it to be an attractive choice to be used for current and future Wireless LAN applications.

\section{REFERENCES}

[1] Azim R, Islam M T and Misran N, "Compact tapered-shape slot antenna for UWB applications," IEEE Antennas and Wireless Propagation Letters, Vol. 10 1190, 2011.

[2] Mobashsher A T, Islam M T and Misran N, "A Novel High-Gain Dual-Band Antenna for RFID Reader Applications," IEEE Antennas and Wireless Propagation Letters, Vol. 9 653, 2010.

[3] Emadian R, Mirmozafari M, Ghobadi C and Nourinia J, "Bandwidth enhancement of dual band-. notched circlelike slot antenna," Electron. Letters, 48 356, 2012.

[4] Ullah M H, Islam M T, M. S. Jit, and N. Misran, "A three-stacked patch antenna using high-dielectric ceramic material substrate,” J. Intell. Mater. Syst. Struct. 23 1827, 2012.

[5] Jung Y K and Lee B, "Dual-Band Circularly Polarized Microstrip RFID Reader Antenna Using Metamaterial Branch-Line Coupler,” IEEE Antennas and Wireless Propagation, Vol. 60 Issue: 2 Page(s): 786 - 791,Feb. 2012.

[6] An W X, Wong H, Lau K L, Li S F and Xue Q, "Design of broadband dual -band dipole for base station antenna," IEEE Transaction Antennas and Propagation, Vol. 60 no 3, pp 1592- 1595, Mar 2012.

[7] Ullah M H, Islam M T and Mandeep J S, “A Compact Wideband Antenna On Dielectric Material Substrate for K Band.," Microwaves \& RF 51 (8), 50-54, 2012,

[8] Tiang J J, Islam M T, Misran N and Mandeep J S, "circular microstrip slot antenna for dual - frequency RFID application ," Progress In Electromagnetics Research, Vol. 120, 499-512, 2011.

[9] Veysi M, Kamyab M and Jafargholi A, "Single-Feed Dual-Band Dual-Linearly-Polarized Proximity-Coupled Patch Antenna," IEEE Antennas and Wireless Propagation Magazine Volume: 53 , Issue: 1 , Page(s): 90 - 96. 27 May 2011.

[10] Mehranpour M, Nourinia J, Ghobadi C and Ojaroudi M, "Dual band notched square monopole antenna for ultrawideband applications," IEEE Antennas and Wireless Propagation Letters, Vol.11 pages 172-175. 3 Feb 2012.

[11] Mursyidul Idzam Sabran , S. K. A. Rahim , Amuda Yusuf Abdul Rahman, Tharek Abdul Rahman , Muhammad Zairil Muhammad Nor and Evizal, "A Dual-Band Diamond-Shaped Antenna for RFID Application," IEEE Antennas and Wireless Propagation Letters, Vol.10 pages 979 - 982 ,2011.

[12] CST Microwave Studio www.cst.com

[13] R\&S ZVL, R\&S ZVL, Vector Network Analyzers, Rohde \& Schwarz.. 